\title{
Entrevista com AbdouMaliq Simone
}

\author{
An Interview with AbdouMaliq Simone
}

\begin{abstract}
AbdouMaliq Simone
AbdouMaliq Simone é um urbanista com interesse particular em formas emergentes de vida coletiva nas cidades do chamado Sul Global. Atualmente, Simone é professora sênior do Instituto Urbano da Universidade de Sheffield e professora visitante de estudos urbanos no Centro Africano de Cidades da Universidade da Cidade do Cabo. As publicações incluem: Para a cidade ainda por vir, Duke University Press, 2004, e City Life de Jacarta a Dakar: Movimentos na encruzilhada: Routledge, 2009, Jacarta: Desenhando a cidade perto: University of Minnesota Press, 2014, New Urban Worlds : Habitando Dissonant Times, Polity 2017 (com Edgar Pieterse) e Improvised Lives: Rhythmms of Endurance in a South Urban (Polity 2018).
\end{abstract}

Tradução

Leonardo Giucci

Dossiê Espaço Urbano e Imaginação Cultural - https://revistaecopos.eco.ufrj.br/

ISSN 2175-8689-v. 22, n. 3, 2019

DOI: 10.29146/eco-pos.v22i3.27418 


\section{ENTREVISTA}

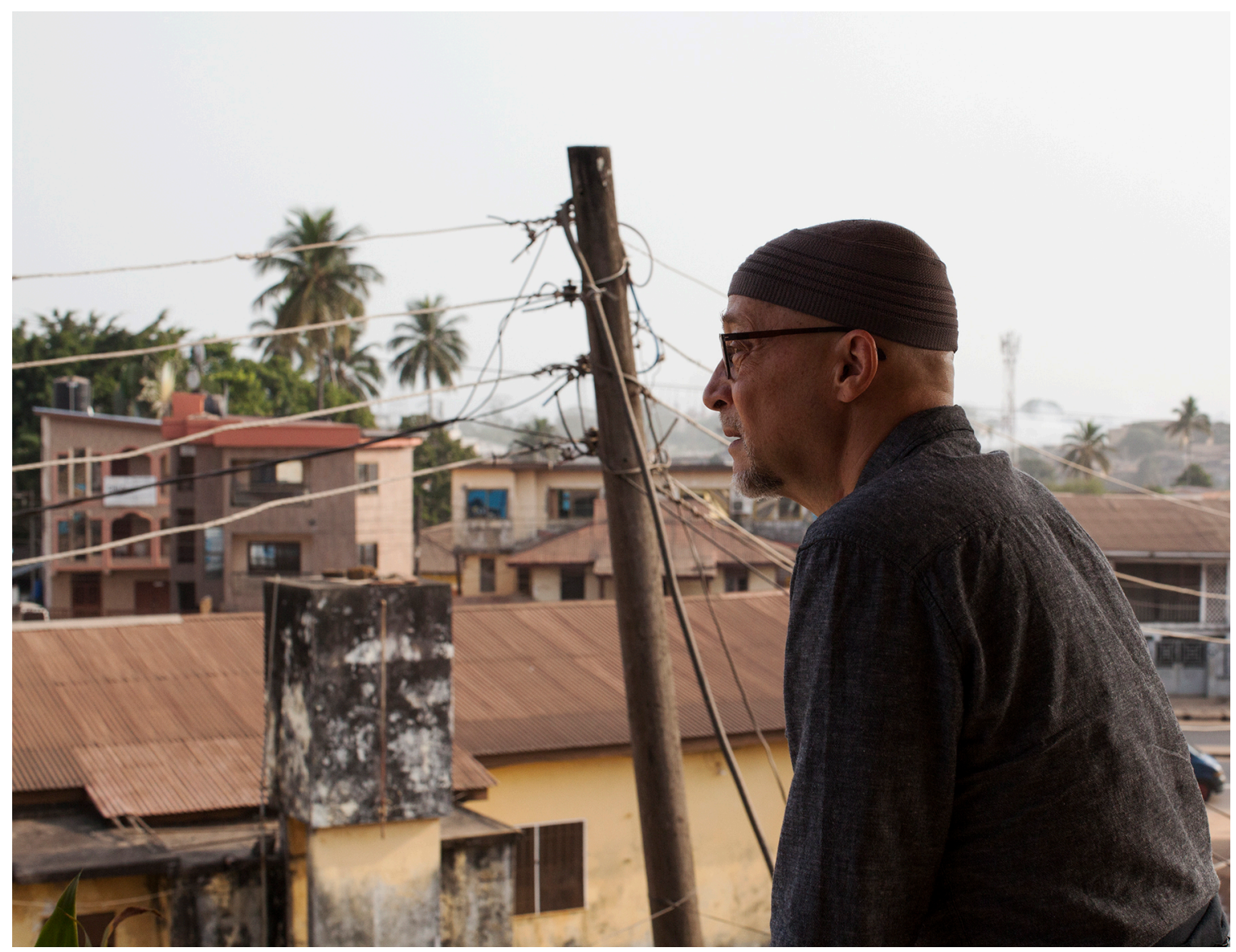

AbdouMaliq Simone é um sociólogo e urbanista que examina os processos não convencionais de urbanização nas extensas regiões urbanas da África, do Sul Global e do sudeste da Ásia. Seu trabalho explora a produção da vida cotidiana das populações urbanas no Sul Global, imaginários de infraestrutura, afeto coletivo, negritude global e histórias do presente para as classes trabalhadoras muçulmanas.

Nesta edição da Revista Eco-Pós, incluímos traduções de duas seções de seu livro mais recente: Vidas Improvisadas: Ritmos de Resistência em um Sul Urbano (Depois do Pós- 
Colonial) ${ }^{1}$. Este trabalho aborda as práticas de intercâmbio social, arranjos técnicos, economia local e a constituição de relações de poder que moldam como cidades heterogêneas são vividas. Nesses locais, os distritos populares são o cenário de operações incertas que acontecem sob o manto da escuridão, gerando alianças estranhas entre corpos, materiais e coisas díspares e expandindo o sensório urbano e suas capacidades de vitalidade. Ao explorar esses processos, Simone se concentra na multiplicidade de relacionamentos e capacidades que caracterizam a operação de tais espaços no dia a dia dessas comunidades, mas que ainda não foram exploradas pelas estruturas formais de governança.

Aqui, nessa entrevista exclusiva realizada por Scott Salmon com o Professor Simone, foi discutido alguns dos principais temas de seu último livro e os conceitos que ele desenvolve - bem como a maneira pela qual sua própria 'vida improvisada' o levou a elaborar estes conceitos.

Revista Eco-Pós: Dado que pudemos traduzir apenas dois capítulos, quais são os temas centrais do seu livro?

AbdouMaliq Simone (AS): O livro foi baseado em uma série de três palestras proferidas na Universidade de Cambridge em 2017. A missão era que as palestras tratassem de questões contemporâneas do pós-colonial, e me pediram para fazer algo que pudesse reconceitualizar o "Sul global urbano", para além de suas referências como um território geográfico e sócio-político específico. 0 objetivo era cruzar certas linhas do pensamento crítico Negro, o Islã e as epistemologias de uma "maioria urbana" para explorar o urbano como um território da imaginação, condições materiais indiferentes às presunções do

1 SIMONE, AdouMaliq. Improvised Lives: Rhythms of Endurance in an Urban South (After the Postcolonial). Cambridge, UK: Polity Press, 2019.

Dossiê Espaço Urbano e Imaginação Cultural - https://revistaecopos.eco.ufrj.br/

ISSN 2175-8689-v. 22, n. 3, 2019

DOI: $10.29146 /$ eco-pos.v22i3.27418 
"humano" e a elaboração de " vidas que valem a pena viver ", não baseadas nas políticas predominantes de assentamento. Além disso, as palestras e o livro foram um experimento na aplicação das sensibilidades do que o Art Ensemble de Chicago chama de "Great Black Classical Music" - a mistura de blues, jazz improvisado, afrofuturismo, dub e baixo - para abordar a importância do "ritmo" como dinâmica urbana. Em outras palavras, a importância das oscilações, improvisação, modulação, harmônia e o conjunto como práticas que compõem realidades e espaços urbanos. A chave para a vida urbana cotidiana não é a especificidade do terreno, não é a definitividade da identidade, é a "chamada e resposta" de setores, atores e materiais divergentes que se respondem, com capacidades e histórias diferenciais, mas com atenção muitas vezes inexplicável e transgressora. Como muitas vezes me perguntam sobre as plataformas metodológicas de meus compromissos com vários campos urbanos, o livro também procurou personalizar esse compromisso, contar histórias que me envolviam diretamente, mas ao mesmo tempo, sem tornar este um "projeto pessoal", e sim como um compromisso de vida toda de deformar as aparentes restrições da história e das expectativas.

A ideia não era tanto exprimir a imagem de um novo mundo, ou um destino claramente compreensível. Em vez disso, a intenção era concentrar-se em processos que manteriam a imaginação funcionando, que sustentariam as capacidades de se seguir em frente. Esse movimento por si só é a condição insuficiente, porém necessária, para gerar o que eu chamei de "algo mais além" - o que ainda está por vir, mas que já pode estar aqui em vidas e lugares considerados desperdiçados ou descartáveis. Afinal, para muitas pessoas pobres, mudar-se é a única opção que elas têm de não serem completamente capturadas por uma vida de pobreza a qual elas sabem muito bem que será provavelmente tudo o que experimentarão. Mas, mesmo nessas condições de opressão, não se pode permitir que isso defina completamente o ato de viver e, portanto, esse ato deve ser removido das racionalidades e dos cálculos de eficácia ou probabilidade. Simplesmente tem de ser feito.

Dossiê Espaço Urbano e Imaginação Cultural - https://revistaecopos.eco.ufrj.br/

ISSN 2175-8689-v. 22, n. 3, 2019

DOI: 10.29146/eco-pos.v22i3.27418 
Muitas das situações do livro concentram-se em realizações incrementais, a capacidade de construir em cima das infraestruturas de vida já existentes. Aqui, o incremental não é uma prática voltada para um destino final, mas a ocasião pela qual os residentes urbanos com quem trabalho sinalizam entre si a disposição de renovar formas de colaboração existentes ou de experimentar novas. 0 incremental é um reflexo da confiança no que se sabe e uma disposição para que essa confiança lide com o imprevisto, sem apagar tudo o que havia antes, para que se entrelace em relações recíprocas de "chamada e resposta", propondo coisas ao mundo a fim de suscitar algo que não seja confirmação ou crítica, mas manifestações inesperadas de possibilidade. Isso é o que eu acho que é resistência - onde você implementa o que sabe em conjunto com outras pessoas cujas habilidades e maneiras de fazer as coisas são diferentes, mas potencialmente aplicáveis, não importando sua genealogia. Através desse processo, novos mundos podem ser construídos.

\section{Revista Eco-Pós: Você poderia expandir um pouco sobre seu conceito de "inabitável"?}

AS: Se as condições do mundo urbano existente tiverem sido amplamente moldadas pela anti-negritude, esse mundo se torna inabitável, não apenas para aqueles mantidos fora das possibilidades de habitação, mas para todos. Independentemente de quão assentados os residentes urbanos estejam através da posse da propriedade, da transformação da terra em patrimônio ou da securitização da vida como fluxo contínuo de renda, a pura presença da negritude como aquilo que permite à cidade ser o local de autoreflexão infunde o espaço urbano com agitação e inquietude incessantes. Não se trata de integrar de maneira mais justa a negritude aos processos de urbanização que tanto dependem de sua exclusão, mas sim de "abolir" a própria base dessa dependência. Inversamente, tanto investimento foi feito para evitar a negritude, fugir dela, escapar de suas múltiplas conotações como aquilo que é tanto não-humano quanto além-humano, que é difícil

Dossiê Espaço Urbano e Imaginação Cultural - https://revistaecopos.eco.ufrj.br/

ISSN 2175-8689-v. 22, n. 3, 2019

DOI: 10.29146/eco-pos.v22i3.27418 
imaginar os termos ou o espaço de sua incorporação, de uma valorização mais justa. Como a epítome daquilo que poderia ser operacionalizado, como aquilo que sinaliza o fim do uso e das possibilidades de fruição humana sendo convertidas nos cálculos de troca, a conversão planetária de tanto espaço em uma arena inútil para a maximização do lucro dificulta a identificação de qualquer terreno existente em que a negritude possa habitar.

É necessária, portanto, uma forma de engajamento que veja essas condições urbanas como não para "nós", como indiferentes às nossas aspirações ou à consolidação da autoreflexividade ou da vida humana. Requer "pensamento Negro", não como um instrumento de salvação, mas como um meio de restituir os potenciais subtraídos no extermínio de mundos pluriversais - através do colonial e do imperial. Mas isso só é possível se o mundo como o conhecemos chegar ao fim. Em outras palavras, os dispositivos de enquadramento, conceitualização e governança que impõem às forças e histórias heterogêneas da vida urbana o pressuposto de interoperabilidade - que todos tenham algo a ver um com o outro através de formas específicas de cálculo, proporcionalidade e significado - deve chegar ao fim, deve ficar inoperante. Além disso, os vernáculos e ferramentas através dos quais tentamos impor um sentido às coisas são fundamentalmente separados de qualquer significado ou objetivo específico, e ainda assim, confiamos neles para traçar relações entre as coisas, para nos localizarmos e medirmos o nosso movimento supostamente "adiante".

Além disso, vivemos em ambientes que excedem nossa capacidade de entendê-los, domesticá-los, entregá-los ao nosso uso e, em seguida, exigem modalidades pelas quais "nós" (seja lá o que for "nós") nos estendemos com e através de uma "terra" cujas dimensões não são nem fortuitas, nem destrutivas, mas onde as disposições dessa extensão permanecem amplamente inexplicáveis. Diante disso, um "nós" deve ser configurado que é sempre menor e maior que o "humano" - de modo que o humano não é capaz de existir como árbitro, o definidor de "relações justas" - relações que simplesmente

Dossiê Espaço Urbano e Imaginação Cultural - https://revistaecopos.eco.ufrj.br/

ISSN 2175-8689-v. 22, n. 3, 2019

DOI: $10.29146 /$ eco-pos.v22i3.27418 
são, mas que podem também ser moldadas para permitir a capacidade de prosperar. As instituições urbanas devem, portanto, basear-se em um contínuo ajustar das relações, de garantir a capacidade dos residentes de participarem desses "ajustes"; para traduzir continuamente o que as pessoas valorizam, como querem se reunir e conviver e que tipos de substratos materiais são necessários para essas aspirações, sem alterar os idiomas nos quais essas aspirações são articuladas.

O desafio, como Arturo Escobar tão bem articula, é como formar territórios de interseção, nos quais o funcionamento do território, da administração e do sistema urbano se baseia na ampliação das capacidades e conhecimentos de seus constituintes entre si, enquanto possibilita um espaço para que essas capacidades diferentes de conhecimento permaneçam diferentes sem conotar uma diferença em termos de valor ou acesso ao sustento material. Esta é a vida que resiste ao cálculo; que não decide as coisas "com certeza", que facilita institucionalmente o "dar e receber" de múltiplas iniciativas, sem acumulação ou endividamento.

Revista Eco-Pós: Qual é a diferença comparado às noções mais familiares de pobreza, escassez e dificuldades?

AS: 0 que estou tentando abordar invocando o "inabitável" é o que mais, se algo, existe "além de" relações imperiais, racistas e coloniais - não "lá fora" como algum tipo de alternativa definitiva, mas "próximo a" e desapegado, não de forma autônoma, mas em ocupar espaços e tempos fracamente guardados, desatendidos, opacos, desperdiçados, mas generativos, capazes de encenar maneiras de fazer coisas que não são impedidas pelas formas existentes de cálculo e valor. Muitas vezes, uma política sobre "o que poderia ser feito" deve ficar longe de anúncios ousados ou grandes manobras.

Dossiê Espaço Urbano e Imaginação Cultural - https://revistaecopos.eco.ufrj.br/

ISSN 2175-8689-v. 22, n. 3, 2019

DOI: $10.29146 /$ eco-pos.v22i3.27418 
Édouard Glissant alertou contra as maneiras pelas quais diferenças de todos os tipos são categorizadas dentro de formatos específicos, como as formas urbanizadas de interlocução - a plataforma da cidade onde se espera que os moradores se anunciem, troquem suas opiniões e deliberem sobre seus antagonismos. $\mathrm{Na}$ forma de soliedariedade intensamente mediada pelo social, a compulsão de conversar, de revelar quem se é, de compartilhar a empolgação de estar presente de maneiras particulares, de expressar gostos e desgostos é a atração onipresente de enumerar a diferença apenas para reafirmar a extensão na qual ela esta categorizada, que toda diferença possa pertencer a um "interior". Em distinção, Glissant afirma um "direito à opacidade", a formas de solidariedade dentro de espaços que nenhum regime comunicativo possa reconhecer. Ao mesmo tempo, as solidariedades precisam ser visíveis, fazer reivindicações, assumir poder, e assim a questão é como pensar nas simultaneidades de ao mesmo tempo agir sob o radar e se infiltrar nas instituições que fazem políticas e governam.

Aqui, uma longa tradição da prática crítica Negra é útil. Hortense Spillers falou sobre as complicadas escolhas estratégicas que os negros das Américas enfrentam em termos de garantir sua resistência. Os negros poderiam insistir em sua humanidade em contextos em que essa humanidade fosse estruturalmente excluída, onde a insistência seria interpretada como evidência de desobediência ou da própria ausência de humanidade, mas que, no entanto, nessa afirmação de vontade, apesar dos reveses e consequências, poderia ser interpretada por um eu negro, sem reconhecimento oficial, como evidência de ser humano. Assim, a afirmação de que vidas negras importam é uma continuação de tal determinação.

Em contraste, a indiferença ao valor de um sujeito humano autoformado poderia se manifestar na capacidade do corpo negro de se estender até os arredores, o terreno e a materialidade de seu mundo limitado de operações. Aqui, uma sintonia extraordinária com as operações da Terra e suas variadas atmosferas e maneiras de ser sinalizou um

Dossiê Espaço Urbano e Imaginação Cultural - https://revistaecopos.eco.ufrj.br/

ISSN 2175-8689-v. 22, n. 3, 2019

DOI: $10.29146 /$ eco-pos.v22i3.27418 
distanciamento da necessidade de ser humano. Aqui, os processos de reprodução social foram experimentados em conjunto com os ritmos de outras formas de vivência.

0 ativismo político pode pensar produtivamente sobre formas emergentes que continuam esse tipo de "duplicidade", como agir simultaneamente sobre e sob radares de todos os tipos. Portanto, o inabitável refere-se às realidades aparentes de dificuldades e repressão que devem ser abordadas, comentadas e combatidas, mas, ao mesmo tempo, coexistem com aspectos e processos da vida urbana que se recusam a ser assentados, que não são primariamente definido por serem ou não "bons" para humanos; onde existe a possibilidade de "vidas dignas de ser vividas" que evitem a atração do humano - dos direitos humanos, desenvolvimento, sustentabilidade e assim por diante.

Revista Eco-Pós: A auto-identidade no contexto da comunidade é um tema importante no livro. Como é circunscrito o processo de auto-formação? Como o desenvolvimento desse conceito se relaciona com sua própria história pessoal?

AS: Assim como as primeiras incursões improvisacionais clássicas de músicos como Coltrane, Dolphy, Coleman, Rivers, Ayler e Shepp, existem "temas" que circulam pela cultura popular, que se tornam "padrões" em um repertório de referências. Em certo sentido, esses padrões funcionam como "padrões", como o que é esperado, respeitado e emulado, definindo implicitamente atos de transgressão, oposição. Tais transgressões e oposições são manobras críticas no estabelecimento de qualquer identidade; longe de deformar a importância da identidade, tais manobras as reconfirmam e prolongam. Então musicalmente, esses padrões poderiam ser apropriados como plataformas para outras excursões, elaborando uma noção de "espaço além" que busca não prejudicar ou opor-se às estruturas musicais desses padrões, mas fornecer então "novos bairros" de operação. Eles poderiam atuar como plataformas de improvisação, nas quais o sujeito poderia torcer, girar, desconstruir a melodia e o tom, como um meio de "sair de casa", aventurarse no mundo maior com a capacidade de responder inventivamente a condições

Dossiê Espaço Urbano e Imaginação Cultural - https://revistaecopos.eco.ufrj.br/

ISSN 2175-8689 - v. 22, n. 3, 2019

DOI: 10.29146/eco-pos.v22i3.27418 
imprevistas, e ainda assim ter certeza de que havia um "lar" para o qual retornar, talvez inevitavelmente mudado por esses empreendimentos, mas mesmo assim identificável. Portanto, é esse sentido de auto-formação que me interessa aqui como uma exposição de identidades urbanas, bem como a minha. A questão é como alguém pode ironicamente "frontear" a identidade como um veículo de viagem ao invés de consolidação; um "bilhete para montar" as ondas de passagens que geralmente são carregadas não apenas de perigo, mas de tédio e banalidade. Sun Ra, por exemplo, desenvolveu uma "marca" clara para sua identidade musical, mas baseada em uma indiferença promíscua em relação ao que ele tocava. Não importava; ele simplesmente queria "viajar pelo espaço" e estava disposto a ser o que fosse necessário, não se subordinando a outras modas ou exigências, mas sim criando uma identidade que era ao mesmo tempo difícil de definir, mas em outro nível, completamente fácil de reconhecer. Portanto, oposição, transgressão, complacência, resistência e dissimulação têm seus usos e tempos, mas, novamente, a importância do ritmo aqui está na capacidade de esticar, estender e retirar

\section{Revista Eco-Pós: Quanto agenciamento podemos atribuir à periferia no contexto de} governos nacionais (frequentemente) repressivos?

AS: É evidente que as periferias são importantes playgrounds para regimes nacionais repressivos. Eles certamente exercem controle substancial sobre a aquisição e uso da terra, disponibilizando-a para as ambições de grandes atores corporativos - fundos especulativos, firmas de ações, mega-especuladores- que compõem as periferias como elementos críticos das assembleias financeiras que continuamente reavaliam o que acontece nessas periferias em termos que excedem em muito as capacidades dos atores municipais e nacionais. As periferias tornam-se simultaneamente depósitos de lixo, áreas de retenção, plataformas de especulação e contextos nos quais as operações corporativas que antes pouco tinham a ver com terras, infraestrutura ou serviços urbanos, começam a

Dossiê Espaço Urbano e Imaginação Cultural - https://revistaecopos.eco.ufrj.br/

ISSN 2175-8689-v. 22, n. 3, 2019

DOI: $10.29146 /$ eco-pos.v22i3.27418 
articular o desenvolvimento de seus ativos e portfólios existentes em direção a produção da própria urbanização. Ao mesmo tempo, no contexto das "periferias reais", a composição dos ambientes sociais e construídos é tão "esparramada", com contiguidades intensas de disjunção, que é difícil traçar uma história coerente sobre para onde as periferias estão indo. As migrações internas e externas convergem de maneiras perturbadoras em diferentes regiões do interior; novos corredores de transporte facilitam a articulação e o destacamento de territórios; as temporalidades frequentemente divergentes de diferentes desenvolvimentos tornam difícil discernir trajetórias claras de ascensão e declínio. Demasiadas funções, dinheiros e políticas discrepantes sentam-se lado a lado, e a elaboração concomitante de como elas devem operar em algum tipo de união forma "estranhas alianças" entre diferentes atores e instituições. Ao mesmo tempo, existem periferias pelas quais ninguém quer realmente assumir alguma responsabilidade oficial, que não se enquadram em jurisdições claras ou, inversamente, caem no âmbito de muitas mãos e, portanto, são constantemente desmontadas para acomodar diferentes interesses e sujeitos. Portanto, aqui, não é necessariamente o agenciamento das periferias que é importante, mas as maneiras pelas quais elas ao mesmo tempo habilitam e paralisam ou desabilitam agenciamentos de tipos específicos e, portanto, requerem experimentos de gerenciamento e desenvolvimento - experimentos que não são necessariamente virtuosos ou destrutivos, mas sim, neste momento, ambivalentes. Uma política diferente, ainda que emergente, é necessária para operar com tanta ambivalência - o que não impede que a polícia esteja sempre à disposição.

Dossiê Espaço Urbano e Imaginação Cultural - https://revistaecopos.eco.ufrj.br/

ISSN 2175-8689-v. 22, n. 3, 2019

DOI: $10.29146 /$ eco-pos.v22i3.27418 